\title{
Electrodynamics of colloidal tin oxyhydrate as a quantum macrosystem
}

\author{
(C) Yury I. Sukharev, ${ }^{1 *}$ Boris A. Markov, ${ }^{2}$ and Inna Yu. Apalikova ${ }^{2}$ \\ ${ }^{1}$ Chelyabinsk State University. Kashirin Brothers St., 129. Chelyabinsk, 454092. Russia. \\ E-mail: Yury_Sucharev@mail.ru \\ ${ }^{2}$ Chelyabinsk Higher Military Aviation Red Banner School of Navigators, a Branch of Military Training \\ Scientific Center Fir Force "Air Force Academy Named after Professor N.E. Zhukovsky and Y.A. Gagarin". \\ Town, 11, 1. Branch VUNTS VVS "VVA". Chelyabinsk, 454015.Russia.E-mail: apal-inna@yandex.ru
}

\begin{abstract}
*Supervising author; ${ }^{+}$Corresponding author Keywords: emission-wave duality, Lagrangian maps, lysegang operator, oxyhydrate gel systems, colloidal clusters, spontaneous pulsation flow, diffuse electric double layer, topological continuum, dissociative-disproportionate mechanism, Whitney theory, caustic geometry, noise States.
\end{abstract}

\begin{abstract}
Pulsation spurts of clusters determining nanocurrent ferroelectric electricity of gel tin oxyhydrates are shown experimentally, which characterizes macroscopic quantum coherent effects induced by a nonstationary magnetic field in the dynamics of high-spin magnetic nanocurrent clusters in a gel matrix.

The polyhedral Coxeter model of the tin oxyhydrate Pattern, which is used to make gel objects, is considered, and specific cluster structures are calculated.

The experimental geometry of Coxeter polyhedra is described by a gram matrix, where the values of the matrix are cosines of the slope angles of the faces of WHITNEY oxyhydrate structures. Matrix description of the structure of the oxyhydrate, for example, for 42 days (165-231 min.) of aging, allowed to quantify the structural features of polyhedra or the so-called Whitney folds, which form the electromagnetic wave fronts of energy caused by nanocurrent polarization of oxyhydrate polyhedra. Quantitatively, the Whitney folds are determined by calculating the trace or hole of the corresponding gram matrix.

The Coxeter polyhedra of the oxyhydrate gel are constructed mainly from cluster five-vertices, which in time can compete isomorphically with the facet 30,20,14,12, and 6 vertices. This determines the fine structure of the gel axiology conformations during aging. The probability of the formation of 30 vertices in the gel of tin oxyhydrate is one of the highest.
\end{abstract}

\section{References}

[1] A.K. Guts. Physics of reality. Omsk: Ed. KAHN. 2012-424p. (russian)

[2] Earnshaw, Samuel (1842). On the Nature of the Molecular Force which Regular the Constitution of the Luminiferous Ether. Trans. Camb. Phil. Soc. 7. P.97-112.

[3] I.E. Tamm. Fundamentals of the theory of electricity. Moscow: Fizmatlit. 2003. 616p. (russian)

[4] Yu.I. Sukharev, I.Yu. Apalikova. Nanotube ferroelectrics gel oxyhydrates. Monograph. Butler's legacy series, book 1. Kazan: Ed. OOO "inv. ed. House Butlerov heritage". 2019. 440p. (russian)

[5] Yu.I. Sukharev, I.Yu. Apalikova, B.A. Markov. Patent for the invention. No. 2018126981 with a priority from 23.07.2018."Method of study nanotech ferroelectric manifestations of gel oxyhydrates of $\mathrm{d}$ - and $\mathrm{f}$ elements and a device for detecting such nanotech pulsing of the ferroelectric manifestations" (patent) the WAC. (russian)

[6] Yu.I. Sukharev, B.A. Markov. Colloid cluster periodic formalism. Monograph. Chelyabinsk: Publishing House. Chelyab. state University. 2019. 214p. (russian)

[7] Yu.I. Sukharev, B.A. Markov. Monograph. Nonlinearity of gel oxyhydrate systems. Ekaterinburg: Uroran. 2005. 468p. (russian)

[8] Yu.I. Sukharev, B.A. Markov. Noise pulsation in oxyhydrate systems. Chelyabinsk: Publishing House. Chelyab. state University. 2012. 160p. (russian)

[9] Yu.I. Sucharev, V.A. Markov. Molecular Physics. 2004. Vol.102. Iss.7. P.745.

[10] I.P. Suzdalev. Nanotechnology: physics and chemistry of nanoclusters, nanostructures and nanomaterials. Moscow: Kom.book. 2006. 5923p. (russian) 
[11] Volovich G.I. analog Circuitry and aparatno digital electronic devices. Moscow: Ed.house Dodeka-XXI. 2005. 528p. (russian)

[12] V.I. Arnold. Theory of catastrophes. Ed.4-e, stereotipnoe. Moscow: editorial URSS. 2004. 128p. (russian)

[13] Yu.I. Sucharev. Wave Oscilation in Colloid Oxyhydrates. Switzerland, UK, USA: Trans Tech Publication LTD. 2010. 497p.

[14] Yu.I. Sucharev, E.V. Taramina, A.L. Kuznetsov, and I.Yu. Apalikova. Stochastic spontaneous burst of clusters in oxyhydrate colloidal system of iron(III) and dynamic viscosity change in time. Butlerov Communications. 2012. Vol.29. No.1. P.22-35. ROI: jbc-02/12-29-1-22

[15] V.S. Anishchenko, V.V. Astakhov, et al. Nonlinear effects in chaotic and stochastic systems. Moscow: Izhevsk. Institute of computer research. 2003. 529p. (russian)

[16] Yu.I. Sucharev. Nonlnearity of Colloid Systems: Oxyhydrate Systems. Switzeuland,UK, USA: Trans Tech Publications. 2007. 433p.

[17] R. Rosenzweig. Ferrohydrodynamics. Moscow: World.1989. 356p. (russian)

[18] Sukharev Yu.I., Markov B.A., Lebedeva I.Yu., A. A. Safronov. Noise almost periodic oscillations in hydroxide application in complex $\mathrm{d}$ - and $\mathrm{f}$ - elements. Butlerov Communications. 2010. Vol.18. No.8. P.36-48. ROI: jbc-01/10-18-8-36

[19] Yu.I. Sucharev, and E.S. Vertsyukh. Comparative schemes of cluster streams in the study of phase portraits of colloid-chemical systems. Butlerov Communications. 2012. Vol.30. No.4. P.1-14. ROI: jbc02/12-30-4-1

[20] Arnold. Features of caustics and wave fronts. Moscow: Fazis. 1996. 562p. (russian)

[21] G.M. Zaslavsky, R.Z. Sagdeev, D.A. Usikov, A.A. Chernikov. Weak chaos and quasi-regular structures. Moscow: Science. 1991. 236p. (russian)

[22] N.B. Uriev. Dynamics of structured disperse systems. Colloid. Log. 1998. Vol.60. No.5. P.662-683. (russian)

[23] Passport 422272-270-42885515 PS. Media transformations Mnogotochie-based E-270. Moscow. CJSC "L-CARD". (russian)

[24] A. Schuster. "On the investigation of hidden periodicities with application to a supposed 26day period of mtteorological phenomena". Terrestrial Magnetism and Atmospheric Electricity. 1898. Vol.3. P.13-41.

[25] A.B. Sergienko. Digital signal processing. 2nd-St.Petersburg.: Peter. 2006. P.751. (russian)

[26] J.M. Haileey. Molecular dynamic simulations. Wiley. 1992. 489p.

[27] A.A. Arsen'ev. Lectures on kinetic equations. Moscow: Science. 1992. 218p. (russian)

[28] J.-R. Authelin, A.P. Mackenzie, D.H. Rasmusen. Water clusters in amorphous pharmaceuticals. Journal of Pharmaceutical Sciences. 2014. Vol.103. No.9. 2663-2672c.

[29] R. Feynman, R. Leighton, M. Sands. Feynman lectures on physics. Vol.5: Electricity and magnetism, Translated from English.(ed.3). URSS. 2004. 304p.

[30] Yu.I. Sucharev, B.A. Markov, T.I. Prolubnikova, I.Y. Lebedeva. Quasi- periodic noice oscillations in oxyhydrates of rare-earth elements. Eurasian Chemico-Technological Journal. 2012. 175c. 